\title{
A spectrometer based on smartphones and a low-cost kit for transmittance and absorbance measurements in real-time
}

\section{Espectrómetro basado en teléfonos inteligentes y un kit de bajo costo para mediciones de transmitancia y absorbancia en tiempo real}

\author{
O. Ormachea ${ }^{*}$, A. Villazón ${ }^{2}$, R. Escalera ${ }^{3}$ \\ 1. Centro de Investigaciones Ópticas y Energías, Universidad Privada Boliviana, Cochabamba 3967, Bolivia \\ 2. Centro de Investigaciones de Nuevas Tecnologías Informáticas, Universidad Privada Boliviana, \\ Cochabamba 3967, Bolivia \\ 3. Centro de Investigaciones en Procesos Industriales, Universidad Privada Boliviana, \\ Cochabamba 3967, Bolivia \\ (*) E-mail: oormachea@upb.edu
}

Received: 02/12/2016 Accepted: 03/07/2017

DOI: $10.7149 /$ OPA.50.3.49053

\begin{abstract}
:
Recently, the use of smartphones has been proposed as a real option for developing measurement instruments in different areas (e.g. bio-sensors, spectroscopy, electro chemical sensor) due to their processing, visualization, connectivity and image capturing capabilities. In this work, we propose the development of a low-cost miniaturized spectrometer that uses the camera of an Android smartphone and processes the images in a self-developed software (spectrometric Android App). It includes a measurement kit with a cuvette holder, an optical fiber with a connecting element, and a high luminous efficiency white LED. The spectrometric Android App allows an initial wavelength calibration and a subsequent calibration for measuring absorbance/transmittance, to obtain spectral curves in real-time. We validated our prototype with a case study in the industrial area, by measuring the concentration of chrome in tanning liquors, and comparing the results with a calibrated conventional spectrophotometer. Thanks to our approach, measurements can be done in-situ and in real-time, thus allowing optimized tanning processes, without requiring expensive measurement equipment.
\end{abstract}

Key words: spectrometry, low cost, smartphones, absorbance, tanning liquors.

\section{RESUMEN:}

Debido a sus capacidades de procesamiento, visualización, conectividad y captura de imágenes, el uso de teléfonos inteligentes ha sido propuesto recientemente como una opción factible para el desarrollo de instrumentos de medición en diferentes áreas (e.g. bio-sensores, espectrometría, sensores electroquímicos). En este trabajo presentamos el desarrollo de un espectrómetro miniaturizado de bajo costo que utiliza la cámara de un teléfono inteligente Android y procesa las imágenes en un software propio de espectrometría (aplicación Android). El prototipo incluye un kit de medición conformado por un porta-cubetas, una fibra óptica con un elemento conector y una fuente LED blanca eficiente de alta intensidad. La aplicación Android permite una calibración inicial en función de la longitud de onda y otra calibración subsecuente para obtener valores de absorbancia/transmitancia que generan curvas espectrales en tiempo real. La validación del prototipo se realizó con un estudio de caso en el área industrial para la medición de concentraciones de cromo en licores de curtido, comparando los resultados con un espectrofotómetro convencional calibrado. Gracias al dispositivo y kit desarrollados, la medición se puede realizar in-situ y en tiempo real, lo que permitiría optimizar el proceso de curtido sin necesidad de adquirir equipos costosos.

Palabras clave: espectrometría, bajo costo, teléfonos inteligentes, absorbancia, licores de curtido. 


\section{REFERENCES AND LINKS / REFERENCIAS Y ENLACES}

[1] S. Ramirez, P. H. Carranza, J. Gutierrez, L. Garcia, S. Hernandez, "Aplicación en medicina de la espectroscopía de infrarrojo cercano", Medicina Interna de México 28, 365-370 (2012).

[2] D. L. Andrews, A. A. Demidov, An Introduction to Laser Spectroscopy: Industrial Applications of Raman Spectroscopy. Springer (1995).

[3] M. Popescu, M. Birlan , R. M. Gherase , A. B. Sonka , M. Naiman , C. P. Cristescu, "Applications of visible and infrared spectroscopy to astronomy", UPB Scientific Bulletin, Series A 3, 107-120 (2012).

[4] P. Ropret, J. M. Madariaga, "Applications of Raman spectroscopy in art and archaeology", Journal of Raman Spectroscopy 45, 985-992 (2014).

[5] F. Anabitarte, A. Cobo, J. M. Lopez-Higuera, "Laser-Induced Breakdown Spectroscopy: Fundamentals, Applications, and Challenges”, ISRN Spectroscopy, 1-11 (2012).

[6] Thorlabs "Cuvette Holder with Four Light Ports" https://www.thorlabs.com/newgrouppage9.cfm?objectgroup_ID=4982

[7] Ocean Optics, "CUV-UV Cuvette Holder" http://oceanoptics.com/product/cuv-uv-cuvette-holder/

[8] D. W. Ball, The Basics of Spectroscopy. SPIE Press (2001).

[9] The Open Source Computer Vision Library (OpenCV) http://opencv.org/

[10] P. Jahoda. MPAndroidChart https://github.com/PhilJay/MPAndroidChart/

[11] A. Bavali, P. Parvin, S. Z. Mortazavi, S. S. Nourazar, "Laser induced fluorescence spectroscopy of various carbon nanostructures (GO, G and nanodiamond) in Rd6G solution", Biomedical Optics Express 6, 1679-1693 (2015). https://doi.org/10.1364/BOE.6.001679

[12] C. R. Escalera, L. Arteaga, A. Baldivieso, R. Vega, "Desarrollo y validación de un método espectrofotométrico/colorimétrico para la determinación de Cromo (III)) en licores residuales de piquelado-curtido“" Investigación \& Desarrollo 6, 88-97 (2006).

[13] Centro de Promoción de Tecnologías Sostenibles (CPTS), Guía técnica de producción más limpia para curtiembres: Bolivia. Natural Resources Management and Development Portal, USAID (2003).

[14] E. W. Rice, R. B. Baird, A. D. Eaton, L.S. Clesceri (Editors), Standard Methods for the Examination of Water and Wastewater: Method 3111 Metals by Flame Atomic Absorption Spectrometry. American Public Health Association. American Water Works Association. Water Environment Federation, (2016).

[15] E. W. Rice, R. B. Baird, A. D. Eaton, L.S. Clesceri (Editors), "Standard Methods for the Examination of Water and Wastewater: Method 3113: Metals by Electro-Thermal Atomic Absorption Spectrometry". American Public Health Association. American Water Works Association. Water Environment Federation, (2016).

[16] C. Alcalde, P. Ormad, J. L. Ovelleiro, Validación de la Metodología para la Determinación de Be, Cd, Co, $\mathrm{Cr}, \mathrm{Mo}, \mathrm{Ni}, \mathrm{Pb}, \mathrm{Sb}$ y Sn en Aguas Continentales por ICP-MS (II). Tecnología del Agua, Madrid, España, (1999).

[17] E. W. Rice, R. B. Baird, A. D. Eaton, L.S. Clesceri (Editors), Standard Methods for the Examination of Water and Wastewater: Method 3500: Chromium, Standard Methods for the Examination of Water and Wastewater. American Public Health Association. American Water Works Association. Water Environment Federation (2016).

[18] M. L. Castro, K. Ikeda y D. Suarez, “Metodología para la Determinación de Cr+3, Anexo II de: Informe Técnico Sobre Minimización de Residuos en una Curtiembre", http://www.bvsde.paho.org/cdromrepi86/fulltexts/eswww/fulltext/gtz/infomini/minianex.html\#anex2

[19] J. A. Perez, M. Pujol, Validación de Métodos Analíticos, Monografía Asociación Española de Farmacéuticos de la Industria. Hewlett Packard, Madrid (2001).

[20] C. Matasaru, "Mobile Phone Camera Possibilities for Spectral Imaging", Master Thesis. University of Eastern Findland. (2014) 


\section{Introduction}

Spectrometry has a wide range of applications in different areas (medicine, industry, astronomy, archeology, among others) [1-5]. Commercial spectrophotometers include special optomechanical systems to place quartz cuvettes. This allows measuring absorbance and transmittance, and therefore generates calibration curves to measure concentrations of specific substances in liquid solutions. Those spectrophotometers are generally bulky and have complex optoelectronic elements and specialized software, thus resulting in high costs.

Miniaturized spectrometers with kits for absorbance and transmittance are available in the market $[6,7]$. Even though these spectrometers allow in-situ measurements (in contrast with conventional bulky spectrophotometers), they remain rather expensive for massive use. Recently, new spectrometers have been developed based on the concept of add-ons for smartphones. However, they have a relatively low spectral resolution (c.a. 5-10 nm) and do not use the sensor of the smartphone camera, but rather an external mini-spectrometer that transmits data to the smartphone, e.g. through Bluetooth. Furthermore, the miniaturized spectrometer and the specialized software remain also expensive.

We propose an approach where, not only the computational power and visualization capabilities of a smartphone are used for spectrophotometric measurements and analysis, but also the smartphone's camera is used as the sensor of a miniaturized spectrometer. The proposed approach, in contrast to conventional spectrometers, does not require its own microprocessor, sensor, or communication module but uses those of any Android smartphone, thus reducing costs. Our spectrometer is clipped to the smartphone for in-situ spectrometric data gathering in real-time.

In this article we present four technological contributions:

- The development of a low cost miniaturized spectrometer that uses a smartphone camera and a measurement kit for absorbance and transmittance.

- The development of an Android App that uses the processing and visualization capabilities of the smartphone, to obtain spectra in real-time.

- The qualitative validation of the proposed spectrometer and kit, through the comparison of absorbance spectrum of Rhodamine 6G dye, obtained with a calibrated commercial spectrophotometer.

- The quantitative validation of the proposed spectrometer and kit, through a case study measuring dissolved chromium in tanning liquors (used in Bolivian tanneries). We used a previously validated method based in visible spectrometry and compared the results with those of a calibrated commercial spectrophotometer.

The article is structured as follows: Section 2 describes the development of the miniaturized spectrometer and measurement kit. Section 3 details the image and data processing performed in the Android App, including the wavelength and absorption calibration. Sections 4 and 5 describe the qualitative and quantitative validation of the proposed spectrometer and measurement kit. Finally, Section 6 concludes the article.

\section{Spectrometer and measurement kit}

A spectrometer is an optical device that decomposes polychromatic light in its monochromatic components generating a spectrum to be analyzed as a function of the wavelength [8]. For absorbance and transmittance measurements, there are commercial kits that can be coupled to conventional spectrometers through an optical fiber, requiring a special light source and a cuvette holder. These elements are in general very costly $[6,7]$.

In the following we describe the development of a low-cost miniaturized spectrometer and measurement kit. The spectrometer uses the camera of a conventional smartphone as a sensor, and the kit is coupled to the spectrometer through a simple clip mechanism.

\section{2.a. Miniaturized spectrometer}

The proposed miniaturized spectrometer is a transmission grating spectrometer (see Figure 1). It is composed by an input slit of approximately $200 \mu \mathrm{m}$ (1); a sliding tube (2) that regulates the distance between the slit and the collimation lens (3) to generate a parallel beam; a support structure (4) to assemble all the previously mentioned parts and the diffraction grating with a period of 1000 
lines/mm (5). Considering the basic mathematical relationship between the period and the diffraction angle, the beam should enter with a $45^{\circ}$ angle with respect to the plate surface of the support structure in order to be completely captured by the CMOS (Complementary Metal-Oxide-Semiconductor) sensor of the smartphone camera as shown in Figure 1.

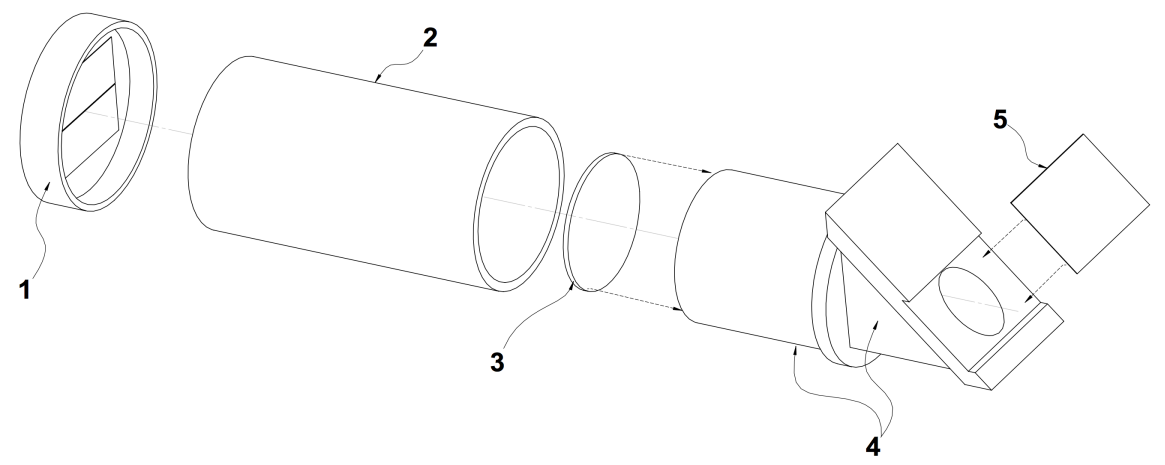

Figure 1: Basic configuration of the proposed transmission miniaturized spectrometer

Figure 2 shows the miniaturized spectrometer printed in 3D with high density black plastic to avoid ambient light to pass through. The device includes a support for optical components and a clip that couples the spectrometer to any smartphone independently of the camera position, thus easing the mounting procedure. Furthermore, the clip has a special black rubber cover to avoid ambient light filtration and to protect the smartphone from scratches.

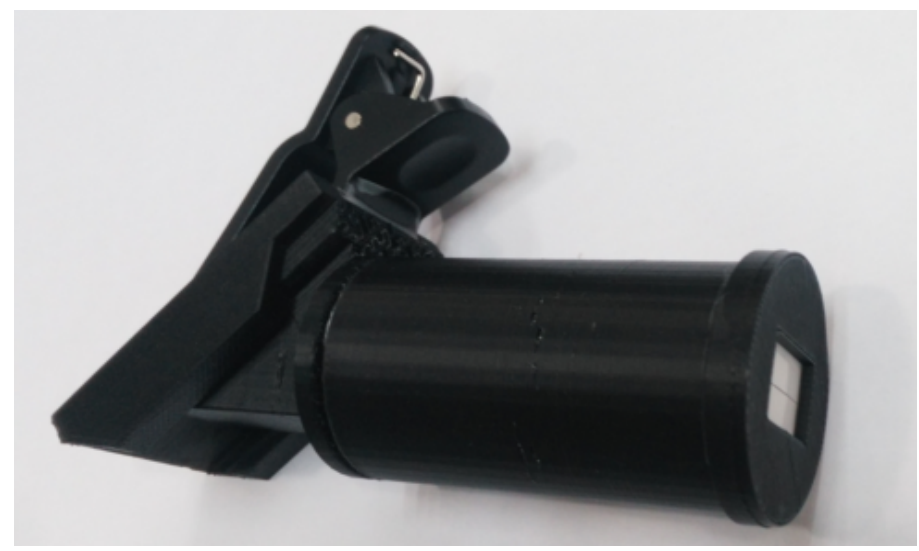

Figure 2: The miniaturized spectrometer printed in 3D.

Table 1 shows the main elements used to build the miniaturized spectrometer and their characteristics. The combination of the grating period, the slit width and the CMOS sensor provides a spectral resolution less than $2 \mathrm{~nm}$.

Table 1: Main elements used in the miniaturized spectrometer

\begin{tabular}{cc}
\hline Elements & Characteristics \\
\hline Collimating lens & Focal length of $4.5 \mathrm{~cm}$ \\
Grating & Period of 1000 lines $/ \mathrm{mm}$ \\
Slit & Approximately $200 \mu \mathrm{m}$ \\
Detector & CMOS sensor of the smartphone camera $(>10 \mathrm{MP})$ \\
\hline
\end{tabular}

\section{2.b. Design and development of the measurement kit}

The measurement kit includes a cuvette holder, an optical fiber, a white LED light source of high intensity, a power supply based on a battery with a potentiometer for controlling the light intensity and a coupling header for the optical fiber connection (see Figure 3). We chose a low-cost plastic optical fiber (POF) without any covering to bring light from the sample to the smartphone camera. Using a non-covered POF does not affect the spectral 
measurements, because the entry of ambient light is minimal (due to the short length of the POF - $40 \mathrm{~cm}$ ) and the electrical/optical noises are eliminated in the software during calibration.

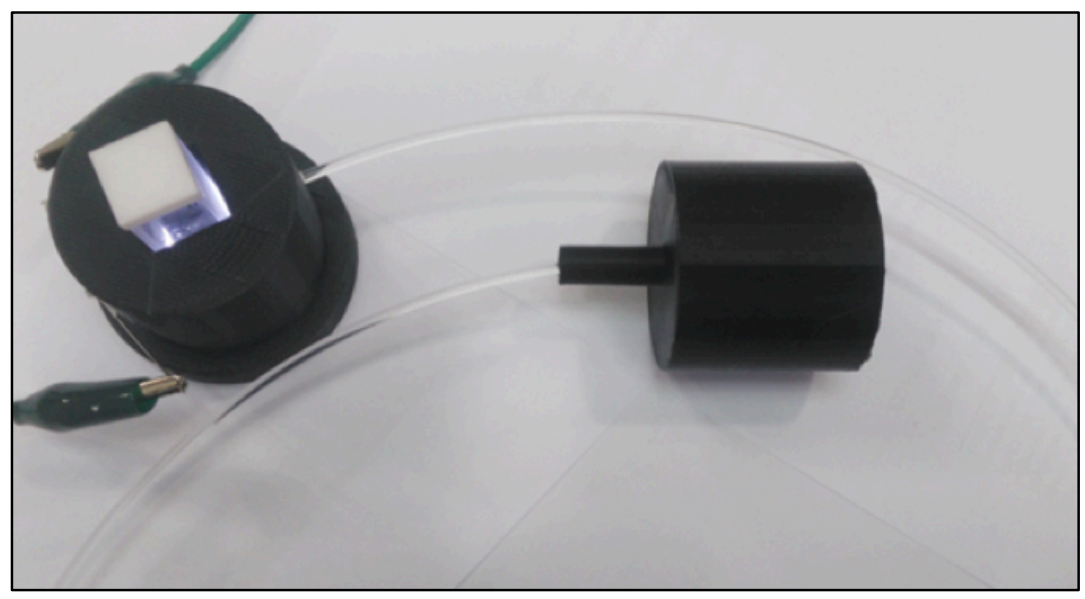

Figure 3: The 3D printed cuvette holder and optical fiber coupling connector.

\section{SpectraUPB: a new spectrometric Android App for smartphones}

To obtain the spectrum, spectrometers require processing the data generated when light reaches the sensor. This is done through special hardware and software that is proprietary and often requires a license. In our approach we propose the use of a standard smartphone camera as a sensor, to obtain digital images that are processed by a newly developed Android App, called SpectraUPB ${ }^{1}$. Besides processing images and generating spectra, the App allows the calibration of the spectrometer based on known spectral reference lines (e.g. mercury lamp) to obtain sufficiently accurate spectral values as a function of wavelengths. The software also gives the possibility to calculate absorbance and transmittance to obtain calibration curves as a function of the concentration of substances of interest contained in liquid solutions. As another interesting feature, the developed spectrometric Android App allows to store and export spectral data and images for off-line analysis, besides being lightweight and easy to use through touch controls. For image processing, we used the OpenCV computer vision library [9] which contains a set of powerful and optimized image processing functions, and the MPChart library [10] was used for the visualization of the spectral curves.

\section{3.a. Image analysis and processing}

Conventional spectrometers use linear array sensors with spectral sensibility from ultraviolet to the near-infrared region. Modern smartphone cameras use CMOS sensors that capture color images. Each pixel, (typically composed by Red Green Blue - RGB) has a different optical sensibility for each component in the visible electromagnetic spectrum. To cover all the visible spectrum, it is possible to either compute the average of the RGB values (which is equivalent to convert the color image to grayscale), or to sum all the values of the RGB components.

In Android, there are two ways to obtain the images from the camera ${ }^{2}$ : (a) from the standard Android Application Programming Interface (API), which works in all devices and returns an image in different formats (YUV, or compressed JPEG format), and (b) using an advanced camera API, which returns an unmodified raw image from the camera sensor, being more suitable for image processing for spectrometry. Unfortunately, the latter is not available to App developers in most of the smartphones and depends on the hardware/software provided by the smartphone constructor. For this reason, we decided to use the standard API with the YUV format, taking into account the fact that the obtained images include correction factors (i.e. a non-linear response as a function of the wavelength) to better fit to human eye perception. It is important to note that other approaches for spectroscopy based on digital cameras, use images in JPEG format obtained from the camera sensor, and according to several authors it has the disadvantage of loss of information due to compression [20]. In our approach, the processing of the images is done using YUV and RGB formats, and JPEG is only used for visualization since it is the default format for displaying images in the screen.

\footnotetext{
${ }^{1}$ The SpectraUPB App is available at the Google Play Store http://play.google.com/store/apps/details?id=edu.upb.cinti.SpectraUPB ${ }^{2}$ https://developer.android.com/reference/android/graphics/ImageFormat.html
} 


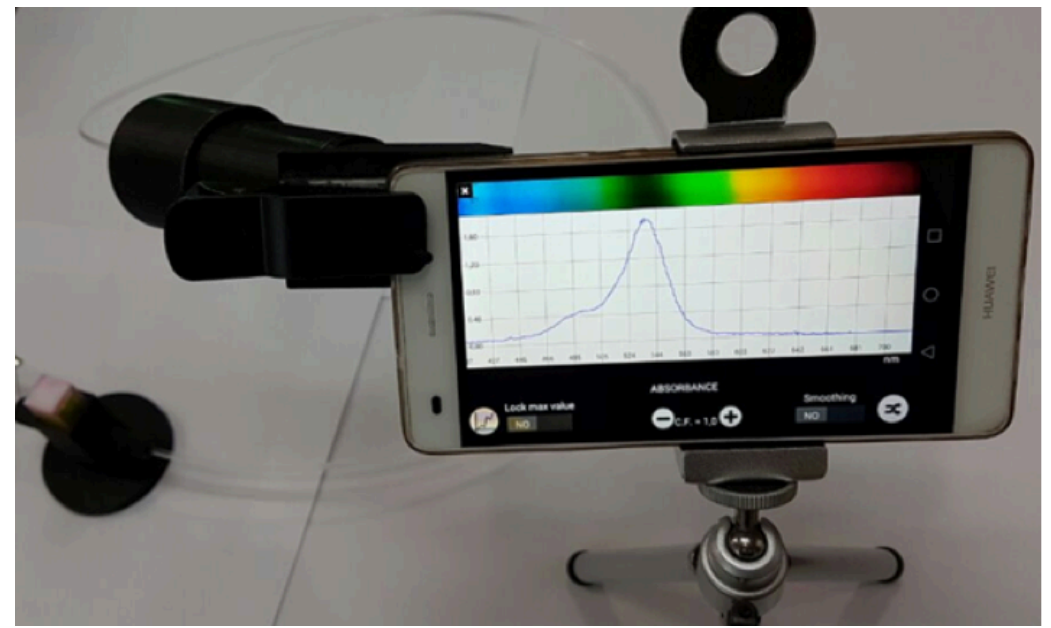

Figure 4: The proposed spectrometer and measurement kit for absorbance and transmittance based on a smartphone.

Since the miniaturized spectrometer has a conventional collimation lens to generate a parallel beam, it can produce spherical aberrations, thus generating curved images. To reduce this effect, the user can select a rectangular region of the area of interest in the image (see Figure 5a). This area defines the new coordinate's origin of the corresponding pixel matrix of size $m \times n$. The selected region is then converted to grayscale and the values for each column of the matrix are added vertically to obtain an array of size $m$ in arbitrary units (see Figure 5b) corresponding to each pixel index in the $\mathrm{X}$ axis. The array is used to generate a line chart representing the spectrum curve, which is however not yet calibrated as a function of the wavelength (see Figure 6a).

$(a)$

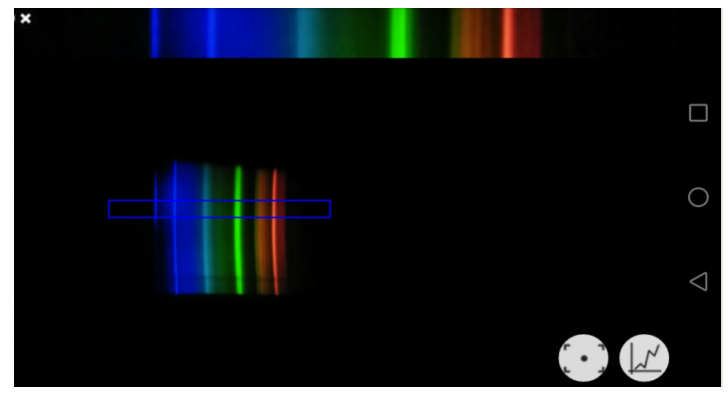

(b)

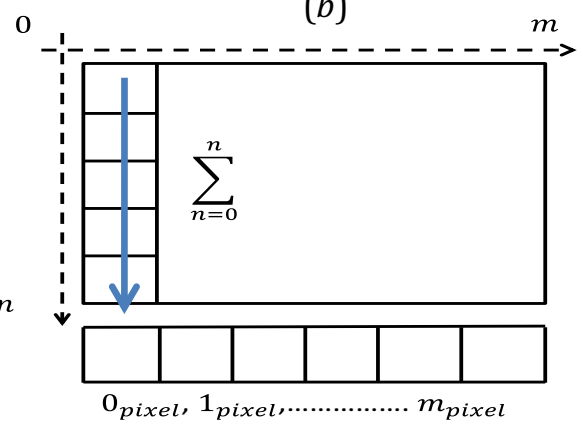

Figure 5: (a) on the bottom the image with spherical aberration and on top the scaled matrix with the user-defined selection, (b) the vertical sum on the selected matrix with the new coordinates origin to obtain the per-pixel array with the spectrum values.

\section{3.b. Wavelength calibration}

The calibration of the spectrometer as a function of the wavelength requires the use of known spectral lines as references. In our approach, we use conventional fluorescent lamps containing mercury (Hg) with well-known spectrum lines. The calibration requires two principal reference lines in the visible region. We chose a peak in the blue and in the green part of the spectrum, at $435.81 \mathrm{~nm}$ and at $546.28 \mathrm{~nm}$, respectively.

To select the wavelength references, we apply a peak detection algorithm ${ }^{3}$ to the spectra curves (see Figure 6a). The user can then visualize and select the peaks corresponding to the related references. Once selected, we extrapolate the values of the wavelengths for each pixel, to have the accurate wavelength in the $\mathrm{X}$ axis (see Figure 6b). The calibrated values are displayed and the user can select any place in the spectrum to obtain the corresponding wavelength values in real time.

\footnotetext{
${ }^{3}$ We adapted the original algorithm implemented in MatLab (http://billauer.co.il/peakdet.html) to Java code for running in Android Operating System.
} 
Concerning the spectral resolution, our prototype can resolve spectral lines with values less than $2 \mathrm{~nm}$ as can be observed in Figure 6b, where two lines are resolved at $434.9 \mathrm{~nm}$ and at $436.1 \mathrm{~nm}$. The spectral resolution can be improved by using a slit with a smaller width and a smartphone with a higher resolution camera.

$(a)$

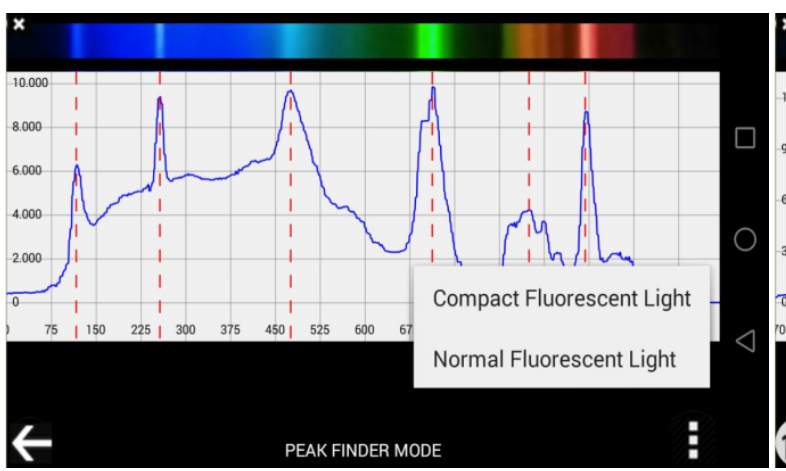

Figure 6: The developed Android App showing the spectral curves (a) the peak detection before wavelength calibration, and (b) the highlighted spectral resolution of less than $2 \mathrm{~nm}$.

\section{3.c. Absorbance calibration}

The absorbance $\mathrm{A}$ is the logarithmic ratio between the incident radiation $I_{0}$ and the radiation $I$ that traverses a sample (see equations (1) and (2)). To calibrate the measured absorbance, we require measuring $I_{0}$ and $I$. As incident radiation $I_{0}$, we use a high luminous efficiency white LED as light source that traverses the cuvette by means of the optical fiber. To correct the electrical noise of the camera and possible radiation interference, we capture the spectral curves with the LED turned off ( $I_{\text {Dark }}$ ). The absorbance A is then calculated with equation (3), using a sample located in the cuvette that produces radiation $I$. The absorption spectrum is finally displayed for further analysis.

$$
\begin{gathered}
I=I_{0} e^{-k L} ; \\
A=\ln \frac{I_{0}}{I} ; \\
A=\ln \frac{I_{0}-I_{\text {Dark }}}{I-I_{\text {Dark }}} ;
\end{gathered}
$$

\section{Qualitative validation: Rodhamine 6G absorption spectrum}

Once the complete prototype was developed (which includes a smartphone running the spectrometric Android software, the miniaturized spectrometer and the measurement kit), we proceeded to the qualitative validation. Figure 4 shows the complete working prototype with the visualization of Rodhamine 6G absorbance spectrum.

For the qualitative validation of the prototype, we compared the spectrum obtained by our prototype with that obtained by a calibrated conventional spectrophotometer (Shimadzu UV-1601). We prepared ethanol solutions of Rhodamine 6G, which is an inexpensive a highly fluorescent dye with a well-known absorption spectrum [11].

With the proposed prototype, we are able to generate spectra of absorbance and transmittance as a function of the wavelength for any measurable solution in the visible light range. For example, in Figure 7 we can observe (a) the absorbance spectrum of the solution of Rhodamine 6G obtained with the conventional spectrophotometer, and (b) the same spectrum obtained with our prototype. Both spectra show similar shapes, where the maximum absorption peak obtained with the calibrated spectrophotometer is at $532 \mathrm{~nm}$, whereas the peak obtained with our prototype is at $531.6 \mathrm{~nm}$. These results are satisfactory because the spectral resolution of the Shimadzu spectrophotometer is $2 \mathrm{~nm}$, similar to our prototype. 
$(a)$

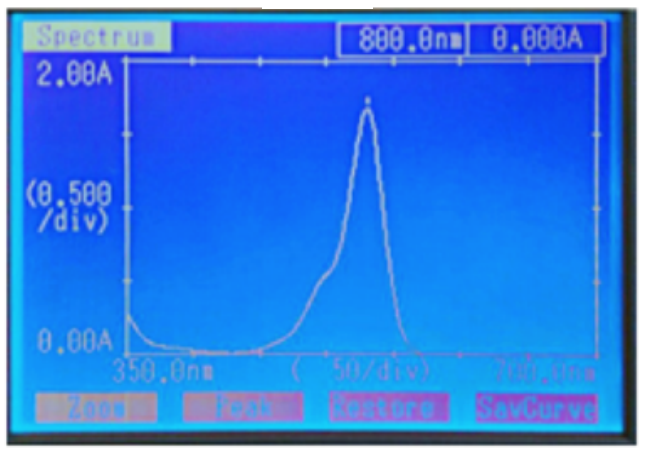

(b)

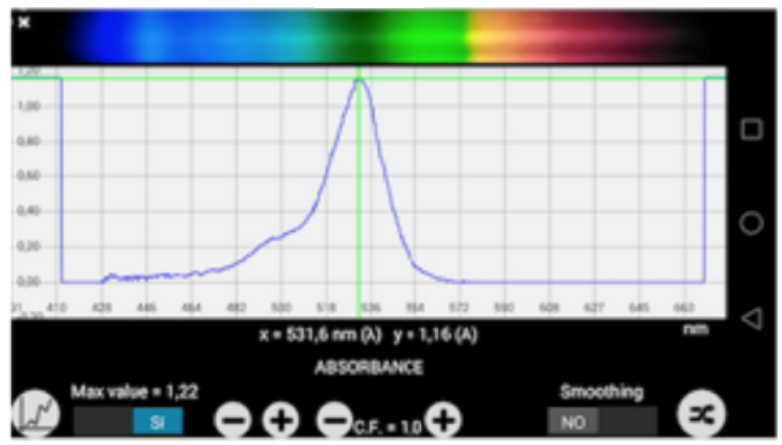

Figure 7: Absorption spectrum of Rhodamine 6G, measured with (a) a calibrated Shimadzu UV-1601 spectrophotometer and (b) our proposed spectrometer prototype

\section{Quantitative validation: Chrome measurements in tanning liquors case ctudy}

For the quantitative validation of the prototype, we chose a case study of a previously validated spectrophotometric measurement of chrome of type $\mathrm{Cr}$ (III) contained in pickling-tanning liquors of small and medium size Bolivian tanneries [12]. We compared the data obtained with the proposed prototype with those generated by a commercial spectrophotometer.

\section{5.a. Case Study background}

The manufacture of leather is an important export industrial sector of the Bolivian economy. The most known and applied process in Bolivia is chrome tanning, because other newly developed technologies are expensive, more complex and the chemicals are difficult to obtain (i.e. long purchase time). The usage of $\operatorname{Cr}(\mathrm{III})$ salts generates huge amounts of wastewaters containing high concentrations of this ion (c.a. $3000 \mathrm{mg} / \mathrm{L}$ ), largely superior to the Bolivian discharge standard of $1.0 \mathrm{mg} / \mathrm{L}$, thus requiring environmental monitoring of the chrome content [13]. Moreover, if direct-recycling of spent picklingtanning liquors is adopted as a Cleaner Production technique, it would be necessary to carry out daily analytical determinations of their ion concentrations, in particular $\mathrm{Cr}(\mathrm{III})$. This measurement requires validated analytical assays in well-equipped laboratories, through calibrated instruments using $\mathrm{Cr}$ (III) standard solutions with chemical reagents of pro-analytical purity [14-18]. These analytical methods measure very low concentrations of $\operatorname{Cr}(\mathrm{III})(0.01$ to $1000 \mathrm{mg} / \mathrm{L})$ and are based on destructive assays where the sample undergoes a series of physical and chemical treatments (acid-digestion, removal of interfering compounds, dilutions and others) to obtain a final solution whose concentration is measured by the instrument. The treatments introduce random and systematic errors that increase the uncertainty and diminish the method's precision.

All these aspects increase the analytical cost of routine/control measurements of liquors that essentially contain high $\mathrm{Cr}$ (III) concentrations (c.a. $2600 \mathrm{mg} / \mathrm{L}$ ). Besides, appropriate installations, expensive qualified and trained personnel are needed, thus increasing operational costs. Alternatively, tanning factories could use the services of specialized laboratories. Nevertheless, costs are expensive for Bolivian tanneries (9-12 \$US/assay) and it is likely that the results would not be obtained with the necessary readiness to control the pickling-tanning process. This situation might severely affect the economic feasibility of the application of direct recycling, especially in small tanning factories.

\section{5.b. Spectrophotometric method for the measurement of $\operatorname{Cr}$ (III) in tanning liquors}

To overcome the above-mentioned difficulties, Escalera et al. developed and validated a non-destructive spectrophotometric method for the measurement of $\operatorname{Cr}(\mathrm{III})$ [12]. By applying this method, the liquor sample requires only a filtration step to eliminate turbidity interference. Moreover, it uses standard solutions prepared with the same commercial chemical reagents currently applied by tanneries, and they require neither special safety conditions nor trained personnel.

In [12], a commercial spectrophotometer (Shimadzu UV-1601) with wavelength scanning device was used to measure the spectra of different working standard solutions and residual liquors obtained from the pickling-tanning of a small tannery of Cochabamba, Bolivia. The scanning range was $190-800 \mathrm{~nm}$. Figure 8 shows the absorbance spectra of working standard solutions with different $\operatorname{Cr}$ (III) concentrations. 
The method satisfies the basic criteria required for validation: proportionality (good linearity and sensibility) within an appropriate range of chromium salt concentrations, usually found in spent tanning liquors (1.85-3.70 g/L); precision (good repeatability: Relative Standard Deviation (RSD) $=0.15 \%$ ); accuracy (no statistical difference compared with official methods: RSD between average values $=0.43 \%$ ) and selectivity (good specificity for $\operatorname{Cr}($ III)).

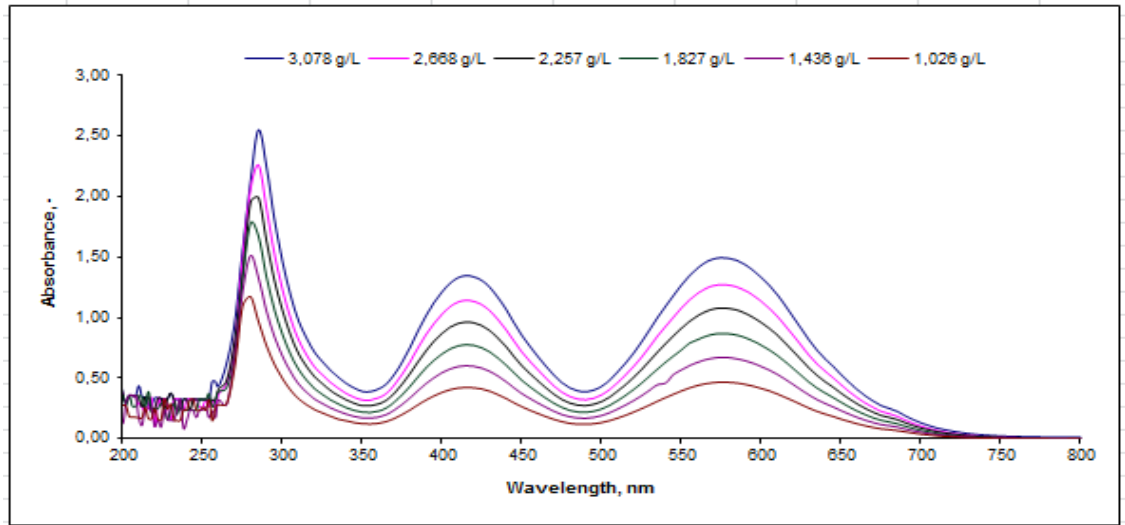

Figure 8: Absorbance spectra of $\mathrm{Cr}(\mathrm{III})$ standard solutions measured with a commercial spectrophotometer.

\section{5.c. Validation of the proposed prototype for $\mathrm{Cr}$ (III) measurement in tanning liquors.}
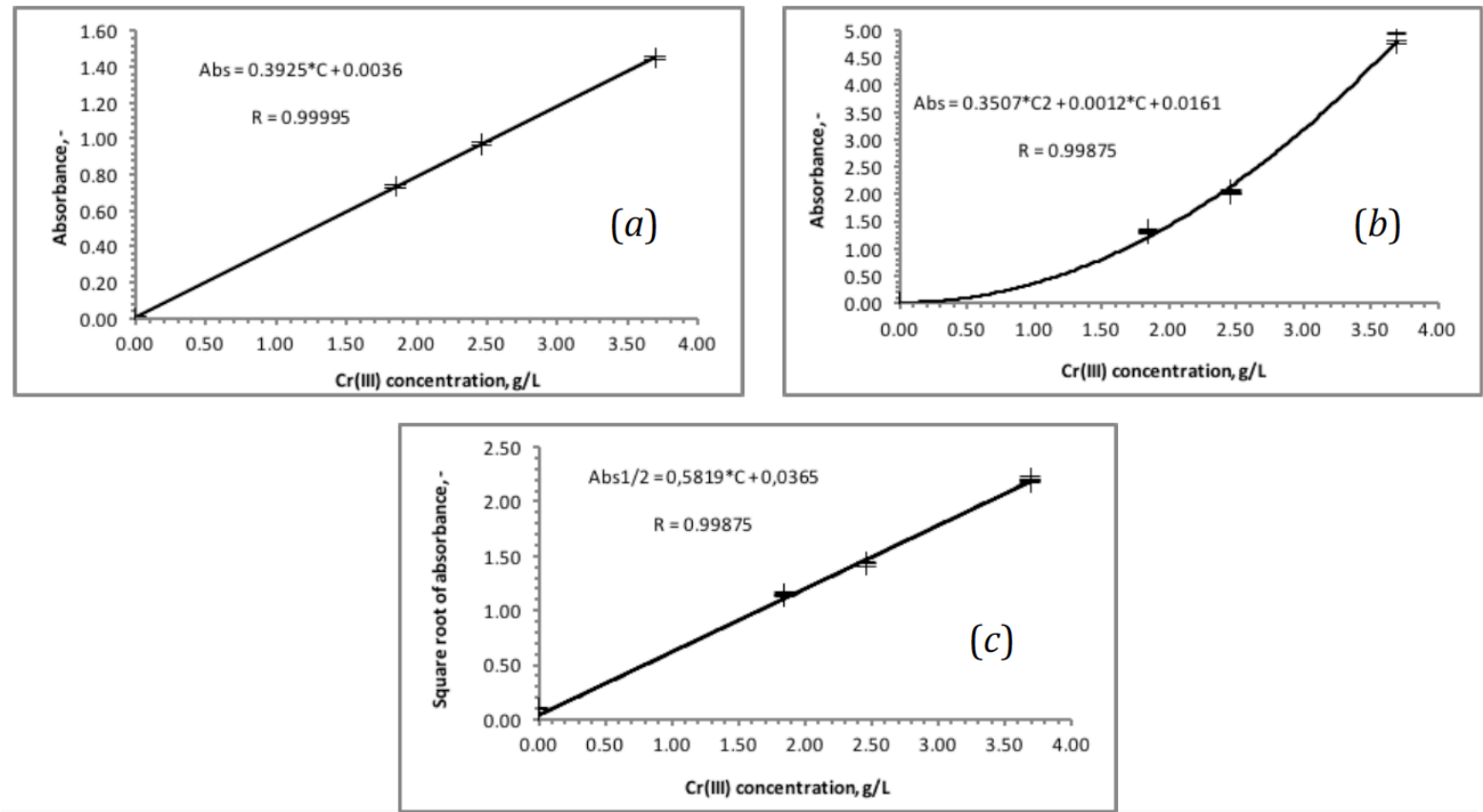

Figure 9: Calibration lines of absorbance vs. Cr(III) concentration measured with: (a) a commercial spectrophotometer, (b) the proposed spectrometer and (c) the proposed spectrometer linearized with the square root of absorbance

For the validation of the prototype we used the same calibrated spectrophotometer. The procedures and chemicals are described as follows:

- Primary standard solution: basic chromium salt containing 17.1\% Cr(III), dissolved in tap water to obtain a $10.3 \mathrm{~g}-\mathrm{Cr}(\mathrm{III}) / \mathrm{L}$ solution. This concentration corresponds to the $\mathrm{Cr}$ (III) supply before the pickling-tanning processes. 
- Working standard solutions: The primary standard solution was diluted with tap water, to obtain working Cr(III) solutions of known concentrations within $1.85 \mathrm{~g} / \mathrm{L}$ and $3.69 \mathrm{~g} / \mathrm{L}$. These concentrations lie within the expected range of spent pickling-tanning liquors.

The peak at $576 \mathrm{~nm}$ was chosen to calibrate both the prototype and the commercial spectrophotometer. We used triplicate independent measurements on working standard solutions to obtain the absorbanceconcentration calibration lines.

The data obtained by the commercial spectrophotometer gives a linear dependency of absorbance vs. concentration (Figure 9a), whereas our prototype measured a quadratic dependency (see Figure 9b). To our understanding, a possible explanation of this quadratic dependency comes from the type of voltage delivered by the RGB sensors of the smartphone, which is a function of the received optical radiation. This relation is linear within certain intervals and is non-linear when the light intensity is low. During measurements, we used low light intensity to avoid light saturation in the camera, thus measuring in the non-linear dependency interval. To compare both dependencies, we linearized the values obtained by our prototype, by computing the square root of the absorbance as a function of concentration (see Figure 9c).

A linearity test was carried out, analyzing the precision of the response factors Y/X (i.e. absorbance/concentration) measured by both instruments. Tables 2 and 3 show the comparison.

Table 2: Response factors measured by the calibrated commercial spectrophotometer

\begin{tabular}{ccc}
\hline $\begin{array}{c}\text { X: } \mathbf{C r}(\mathbf{I I I}) \text { concentration, } \\
\mathbf{g} / \mathbf{L}\end{array}$ & $\mathbf{Y :}$ Absorbance & $\mathbf{Y} / \mathbf{X}$ \\
\hline 1.85 & 0.736 & 0.397 \\
1.85 & 0.736 & 0.397 \\
1.85 & 0.736 & 0.397 \\
2.46 & 0.970 & 0.392 \\
2.46 & 0.970 & 0.392 \\
2.46 & 0.970 & 0.392 \\
\hline Average & & 0.394 \\
Standard deviation & & $2.30 \mathrm{E}-3$ \\
RSD & & $0.586 \%$ \\
\hline
\end{tabular}

Table 3: Response factors measured by the proposed prototype

\begin{tabular}{cccc}
\hline $\begin{array}{c}\text { X: Cr(III) Concentration, } \\
\text { g/L }\end{array}$ & Y: Absorbance & $\mathbf{Y}^{\mathbf{1 / 2}}$ & $\mathbf{Y} \mathbf{1 / 2} \mathbf{X}$ \\
\hline 1.85 & 1.32 & 1.15 & 0.602 \\
1.85 & 1.29 & 1.14 & 0.595 \\
1.85 & 1.34 & 1.16 & 0.607 \\
2.46 & 2.07 & 1.44 & 0.569 \\
2.46 & 2.01 & 1.42 & 0.561 \\
2.46 & 2.01 & 1.42 & 0.561 \\
3.69 & 4.81 & 2.19 & 0.584 \\
3.69 & 4.75 & 2.18 & 0.580 \\
3.69 & 4.93 & 2.22 & 0.591 \\
\hline Average & & & 0.583 \\
Standard deviation & & & $1.71 \mathrm{E}-2$ \\
RSD & & & $2.93 \%$ \\
\hline
\end{tabular}

The Relative Standard Deviations (RSD) of the data measured by both instruments are smaller than 5\%, the limit value for linearity tests based on response factors [19] (0.586\% for Shimadzu UV-1601 y 2.93\% for the prototype). Moreover, the average of the response factor values (see Table 2 and Table 3 ) are very close to the slopes of the calibration lines as shown in Figure 9a and Figure 9c (0.394 vs. 0.392 and 0.583 vs. 0.582 , respectively). These results show that both methods are linear over an appropriate range of 
Cr(III) concentrations expected in spent pickling-tanning liquors, once the prototype response has been linearized.

Triplicate measurements of the Cr(III) concentration in tanning liquors were also carried out using both instruments, analyzing the RSD between the average values (see Table 4). The average values are very close $(2.15 \mathrm{~g} / \mathrm{L}$ for the commercial spectrophotometer and $2.16 \mathrm{~g} / \mathrm{L}$ for the prototype) and their RSD is very small $(0.394 \%)$. These results demonstrate that the prototype is qualified to measure $\operatorname{Cr}($ III) in residual tanning liquors.

Table 4: Cr(III) concentrations in tanning liquors measured by a calibrated commercial spectrophotometer and the proposed prototype

\begin{tabular}{|c|c|c|}
\hline $\mathrm{N}^{\circ}$ of measurement & $\begin{array}{c}\text { Cr(III) concentration, } \\
\text { Shimadzu UV-1601, } \\
\text { g/L }\end{array}$ & $\begin{array}{c}\text { Cr(III) concentration } \\
\text { Prototype, } \\
\text { g/L }\end{array}$ \\
\hline 1 & 2.146 & 2.152 \\
\hline 2 & 2.151 & 2.152 \\
\hline 3 & 2.149 & 2.178 \\
\hline Average & 2.149 & 2.161 \\
\hline RSD between average values & & \\
\hline
\end{tabular}

\section{Conclusion}

We developed a miniaturized spectrometer that leverages the camera of a smartphone and the computing power to process the images and visualize spectral curves. The spectrometer is coupled with a measurement kit through a non-covered plastic optical fiber which allows non distorted absorbance and transmittance measurements. The spectrometric Android App that we implemented, processes the images captured by the camera sensors, enables wavelength and absorption calibration, and displays real-time spectral curves. The presented prototype is a low-cost solution compared to existing spectrometers and measurement kits, which in addition have lower spectral resolution. We performed both qualitative and quantitative validation of our prototype by comparing absorption spectra against a calibrated conventional spectrophotometer. Our Case Study measuring the concentration of chrome in tanning liquors showed that our approach allows in-situ and real-time spectral analysis, while keeping the measurements simple to use and not requiring specialized personnel. These encouraging results demonstrates that the use of smartphones can lead to the development of low-cost spectrometric measuring instruments that are applicable to several science and engineering fields.

\section{Acknowledgements}

The authors want to thank Miguel Carballo for his help in the Android App development and Grover Zurita and Oscar Urquidi for the design of the 3D printed prototype. This work was funded by the research fund of Universidad Privada Boliviana (UPB). 